\title{
EL PRESIDENTE \\ DE LA COMUNIDAD DE MADRID
}

ANTONIO TORRES DEL MORAL

Catedrático de Derecho Constitucional UNED 


\section{SUMARIO}

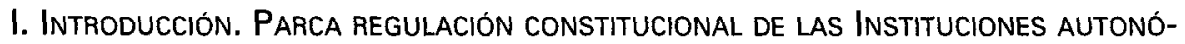

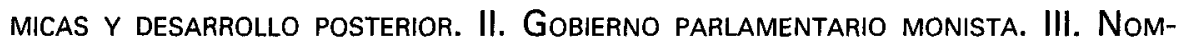
BRAMIENTO deL PRESIDENTE Y FORMACIÓN DEL GoBIERNo. El procedimiento de nombramiento del Presidente en el contexto del Derecho constitucional autonómico. Fase de consultas previas. Propuesta de candidato. Presentación del programa de Gobierno y debate. Votación de investidura. Nombramiento regio del Presidente y toma de posesión. Nombramiento y cese de los restantes miembros del Gobierno. IV. Rasgos generales del Estatuto jurídico del Presidente. Status y funciones. Representación de la Comunidad Autónoma y del Estado. Dirección de la actividad del Gobierno. Naturaleza del órgano. Delegación de funciones presidenciales. Régimen de incompatibilidades. Fuero penal y civil. Ausencias, incapacidad y cese. Presidente interino y Presidente en funciones. V. Responsabilidad Politica. VI. Disolución de la Asamblea por el Presidente de la Comunidad. VII. Conclusión: ¿Liderazgo del Presidente o coleGIALIDAD DEL Gobierno? 


\title{
EL PRESIDENTE DE LA COMUNIDAD DE MADRID
}

\author{
POR \\ ANTONIO TORRES DEL MORAL \\ Catedrático de Derecho Político \\ Universidad Nacional de Educación a Distancia
}

\section{INTRODUCCIÓN}

\section{PARCA REGULACIÓN CONSTITUCIONAL DE LAS INSTITUCIONES AUTONÓMICAS Y DESARROLLO POSTERIOR}

La Constitución española aborda la estructura institucional de las Comunidades Autónomas que pudieran crearse ulteriormente en el artículo 152.1, párrafo 1, que dice asi:

«1. En los Estatutos aprobados por el procedimiento a que se refiere el artículo anterior, la organización institucional autonómica se basará en una Asamblea Legislativa elegida por sufragio universal con arreglo a un sistema de representación proporcional que asegure, además, la representación de las diversas zonas del territorio; un Consejo de Gobierno con funciones ejecutivas y administrativas; y un Presidente, elegido por la Asamblea, de entre sus miembros, y nombrado por el Rey, al que corresponde la dirección del Consejo de Gobierno, la suprema representación de la respectiva Comunidad y la ordinaria del Estado en aquélla. El Presidente y los miembros del Consejo de Gobierno serán políticamente responsables ante la Asamblean.

Lo primero que se observa es que el precepto transcrito se refiere únicamente a las Comunidades cuyos Estatutos siguieran el curso del artículo 151, esto es, las de acceso rápido a una autonomía plena. 
A ellas se les añade, por efecto de la Disposición Transitoria Segunda, Cataluña, País Vasco y Galicia, la elaboración de cuyos Estatutos siguió las pautas del artículo 151.2 sin necesidad de los trámites del 151.1.

Pero inmediatamente después llama la atención que no existe un precepto similar para las Comunidades de acceso por la vía del artículo 143 o de autonomía inicial menos plena. Lo que, en términos funcionales, llevaba al dislate de que éstas eran más autónomas que aquéllas en cuanto a la dotación institucional, al no existir precepto constitucional alguno de obligatoria observancia.

El buen sentido ha reconducido la situación a la extensión de los términos del artículo 152.1 a todas las Comunidades Autónomas. Interpretación perfectamente plausible, además por cuanto el silencio del mencionado precepto en relación a las Comunidades de autonomía inicial menos plena, no se debía a la voluntad del constituyente (ni de la Constitución), de ampliarles el principio dispositivo, sino a la duda de primera hora acerca de si estas Comunidades estarían dotadas de potestad legislativa y, por ende, de si tendrían o no Parlamento. Cuando, como resultado de los Pactos Autonómicos de 1981 entre el Gobierno de UCD y el PSOE, principal partido de la oposición, se generalizó el sistema autonómico de modo tendencialmente homogéneo, todas las Comunidades Autónomas asumieron la referida potestad y se dotaron de Asamblea Legislativa1.

Al final, por consiguiente, ha habido una homogeneización ${ }^{2}$ de esta estructura institucional autonómica básica ${ }^{3}$ señalada por la Constitucional relativa a los dos clásicos poderes, Ejecutivo y Legislativo. A partir de ahí y excepcionando el Poder Judicial, que es único para todo el Estado, las Comunidades Autónomas han dispuesto, o no, la creación de otros órganos, como Defensor del Pueblo, Consejo Consultivo o Tribunal de Cuentas.

1 Cfr. en otros muchos, BAR, A.: "Comentario al artículo 21", en BERMEJO VERA, J: (Dir.) Comentarios al Estatuto de Autonomía de Aragón (Instituto de Estudios de Administración Local Madrid, 1985, pág. 226); Ruız-Rıco RuIz, G.: La forma de gobierno en Andalucía (Junta de Andalucía y Tirant lo Blanch. Valencia, 1999, p. 25 y 246-247); y CONTRERAS, M.: "El estatuto jurídico del Presidente", en LóPEz RAMón, F. (Dir.): Estudio sistemático de la Ley del Presidente y del Gobierno de Aragón (Cortes de Aragón. Zaragoza, s.f., págs. 49-50).

2 De homogeneización, mimetismo y simetría, como asimismo de adopción del modelo gubernamental central, habla Ruız-Rıco Ruiz, G., op. cit. (págs. 245248).

3 En efecto, el artículo 142.1 de la Constitución dice que "la organización institucional autonómica se basará en...". 


\section{GOBIERNO PARLAMENTARIO MONISTA}

Despejada la anterior incógnita, es de resaltar que el texto constitucional, aunque parco en palabras $y$ en nominación de instituciones, contiene elementos suficientes para iniciar nuestro estudio. A saber:

a) El Consejo de Gobierno tiene funciones ejecutivas y administrativas.

b) El Presidente dirige el Consejo de Gobierno. Es, pues, su Presidente.

c) Pero, como le corresponden igualmente funciones representativas, es Presidente de Comunidad.

d) El Presidente debe ser miembro de la Asamblea Legislativa.

e) El Presidente es elegido por dicha Asamblea.

f) Tanto él como los Consejeros del gobierno son políticamente responsables ante la Asamblea Legislativa.

Tiene sentido, pues preguntarse sobre si los Gobiernos autonómicos son monistas o dualistas, esto es, si se distingue en ellos, o no, un Presidente de la Comunidad además del que lo sea del Gobierno, al modo como en el Derecho comparado se detecta en los sistemas parlamentarios.

Aunque la respuesta ha dividido a la doctrina, ha acabado siendo mayoritaria $-y$ en esa línea se mueve este trabajo- la que entiende que, si bien las funciones gubernamentales y presidenciales (de la Comunidad) son perfectamente diferenciables, el hecho de que concurran en una sola persona y que ésta sea políticamente responsable ante la Asamblea Legislativa sin distinción de las funciones o actividades por las que lo es, permite hablar de Gobierno monista, no sin enfatizar el carácter poliédrico de la institución que estudiamos.

Claro que esta cuestión nos lleva a la de si el sistema de Gobierno resultante es parlamentario o presidencial. Problema muy debatido por la doctrina, la cual se inclina mayoritariamente - $y$ éste es también mi caso- por calificarlo como parlamentario. Pero no son pocos los matices que se le añaden. Así, sin ánimo alguno de exhaustividad, mencionaremos: 
1. M. Revenga lo califica como parlamentario4. J.R, Montero y J. María Morales añaden que es de ejecutivo monista ${ }^{5}$. Algo más complejo, pero coincidente en el fondo con esta posición, se muestra R. Chueca, según el cual no estamos ante un sistema parlamentario, sino ante un sistema de relación entre el Ejecutivo y el Legislativo que se desenvuelve de acuerdo con las reglas del modelo de Gobierno parlamentario ${ }^{6}$.

2. C. Viver i Pi-Sunyer prefiere definirlo negativamente, como no presidencial?.

3. Es un sistema híbrido, concluyen varios autores. A. Ribas entiende que no es un sistema presidencial ni parlamentario puro; esto último apoyado principalmente en la inicial carencia, por parte del Ejecutivo, de la facultad de disolución de la Cámara ${ }^{8}$. A. Bar lo llama forma híbrida, compleja y, hasta cierto punto, contradictoria, dictamen propiciado por el mismo motivo de la inicial indisolubilidad del Parlamento Autonómico ${ }^{9}$. También G. Cámara termina hablando de sistema híbrido después de llamar la atención, muy razonablemente, sobre la necesidad de incluir en el análisis no sólo los preceptos jurídicos literales, sino también los datos sociopolíticos de funcionamiento del sistema, los cuales acentúan los caracteres presidenciales ${ }^{10}$. E igualmente M. Martínez Sospedra, el cual concluye así después de negar la pureza de su monismo, sin ser tampoco un parlamentarismo dualista, como tampoco un sistema presidencial ni convencional11. En fin, G.

4 Revenga, M.: «Notas sobre el procedimiento de designación de Presidente del órgano colegiado ejecutivo de las Comunidades Autónomas", en VV.AA.: I Simposio Internacional de Derecho Autonómico (Generalitat Valenciana. 1988, pág. 608).

5 Montero, J. R. y Morales, J. María: «El sistema parlamentario de la Comunidad Autónoma de Andalucía: un análisis comparado", en VV.AA.: I Simposio... Op. cit. (págs. 562-563).

6 ChuecA, R.: «Los mecanismos de gobierno parlamentario en la Comunidad Autónoma de Aragón», en López Ramón, F. (Dir.): op. cit. (pág. 116).

7 Viver i PI-SunYer, C.: "La figura jurídica del Presidente de la Generalitat a I'Estatut d'Autonomia de Catalunya", enMoLAs, I. (Ed.): Comentaris juridics a l'Estatut d'Autonomia de Catalunya (Edicions 62, Barcelona, 1982, págs. 74-75).

8 RiBas, A.: El Estatuto de Autonomía de las Islas Baleares (Universidad de les Illes Balears, Mallorca, 1998, págs. 180-182).

9 BAR, A.: "Comentario al artículo 21", op. cit. (págs. 226-227).

10 CAmara, G.: "El Poder Ejecutivo de la Comunidad Autónoma de Andalucía", en Cámara, G. y otros: El Estatuto de Andalucía. III - El Gobierno y la Administración (Ariel, Barcelona, 1990, págs. 14-16.

11 Martinez Sospedra, M.: Derecho Autonómico Valenciano (Generalitat Valenciana, 1985, págs. 215-222). 
Ruiz-Rico habla de un sistema parlamentario, pese a la indisolubilidad parlamentaria de primera hora, pero con rasgos presidenciales, sobre todo en las Comunidades en las que existe investidura automática del Presidente en determinadas circunstancias, lo cual, sin embargo, no le lleva a considerar semipresidencialista el sistema, sino más bien como parlamentario "de Canciller»" 12.

\section{NOMBRAMIENTO DEL PRESIDENTE Y FORMACIÓN DEL GOBIERNO}

\section{El procedimiento de nombramiento del Presidente en el contexto del Derecho constitucional autonómico}

Las variantes que ofrece el Derecho constitucional autonómico respecto de la investidura del Presidente de la Comunidad (que lo es también del Consejo de Gobiernol giran en torno a dos elementos: dónde se residencia la iniciativa para hacer la propuesta de candidato cómo se soluciona el fracaso de los sucesivos intentos.

En cuanto al primero, la mayoría de los Estatutos de Autonomía siguen el sistema que la Constitución establece para el Presidente del Gobierno de la Nación: la propuesta la hace un órgano unipersonal investido de auctoritas: el Rey en un caso, el Presidente de la Asamblea Legislativa en el otro. En cambio, en las Comunidades de Asturias, Castilla y León, Extremadura, Valencia y País Vasco tienen la facultad de propuesta los grupos parlamentarios.

Por lo que se refiere al segundo elemento mencionado, también son mayoría los Estatutos que se inclinan por la disolución de la Asamblea Legislativa y la convocatoria de nuevas elecciones. Pero no hay tal disolución en Andalucía, Navarra y Castilla-La Mancha, en las cuales queda automáticamente investido el candidato del partido con mayor número de escaños. Entre las comunidades del primer grupo (con disolución automática del parlamento autonómico), las más acortan el mandato de la nueva Asamblea al que tuviera la disuelta; en cambio algunas -País Vasco, Cataluña y Galicia- no establecen dicha limitación.

Dicho está, por tanto, implícitamente, cuál es el procedimiento seguido por el Estatuto de Autonomía de la Comunidad de Madrid, ali-

12 Rulz-Rico Ruiz, G.: Op. cit. (págs. 19-23 y 248-252). 
neado siempre con la mayoría. Está puntualmente descrito en su artículo 18, el cual sólo ha sufrido un retoque de estilo absolutamente intrascendente en relación al fondo de la cuestión que comentamos. Por lo demás, tal procedimiento es muy similar al dispuesto por la Constitución española para la investidura del Presidente del Gobierno central, salvo en el acortamiento autonómico del mandato de la Asamblea Legislativa resultante de la disolución automática de una anterior por la no investidura de ningún candidato. Esto nos permite $-y$ hasta nos obliga- a establecer los oportunos paralelismos entre la Constitución y el Estatuto madrileño.

La singularidad de la Constitución vigente respecto de todo el constitucionalismo histórico español en punto a la formación del Gobierno viene deparada por la nítida separación entre el proceso de nombramiento del Presidente del Gobierno y el de los demás miembros que lo integran, así como por la índole enteramente parlamentaria del primero de ellos. Es en el primer momento, el del nombramiento del Presidente, donde se ventila de hecho la configuración final del Gobierno y su programa político. Es por eso el momento política y jurídicamente sustantivo.

El Estatuto madrileño, por mímesis de la Constitución, prevé dos formas de nombramiento de Presidente del Gobierno, que podemos denominar ordinaria y extraordinaria. El procedimiento ordinario procede después de cada renovación de la Asamblea Legislativa y en todos los supuestos estatutarios de dimisión o cese del Presidente, salvo si se produce por la aprobación de una moción de censura; hay que agregar los casos de condena penal por sentencia firme y de incapacidad física y psíquica irreversible, médicamente dictaminada. La forma extraordinaria es la resultante de la aprobación de una moción de censura por la Asamblea.

La forma ordinaria, una vez producida la vacante en la Presidencia del Gobierno, discurre por las siguientes secuencias:

1. Consultas del Presidente de la Asamblea con los representantes de los Grupos políticos con escaños parlamentarios.

2. Propuesta de un candidato.

3. Presentación del programa de Gobierno y debate.

4. Investidura del candidato por la Asamblea o reinicio del proceso.

5. Nombramiento por el Rey del candidato investido. 
Fase de consultas previas

EI Derecho comparado ofrece pocos ejemplos del requisito de consultas previas a la hora de proponer candidato. Su función es la de proporcionar información fidedigna del parecer de los Grupos integrantes de la Cámara acerca del candidato que están dispuestos a respaldar. En esta fase, el Presidente de la Asamblea Legislativa de Madrid goza de una discrecionalidad limitada ${ }^{13}$ en la dirección del proceso. Tiene, en efecto, la iniciativa y, frente a lo prescrito en otros Estatutos Autonómicos, no está compelido a presentar candidato en plazo. Pero, de un lado, debe actuar con diligencia por la naturaleza misma del problema que se trata de solventar $y$, de otro, no decide las personas que debe consultar, sino que éstas son designadas por los Grupos políticos con escaños en la Cámara, se entiende que una por cada Grupo.

¿Puede el Presidente de la Asamblea Legislativa ampliar sus consultas más allá de los Grupos políticos con representación parlamentaria? La respuesta deber ser matizada. En efecto, si bien no hay prohibición estatutaria al respecto, la información sobre el parecer y la voluntad de la Cámara sólo los representantes políticos mencionados por la Constitución y por la legislación autonómica, en su caso, pueden proporcionarla. Pero esas otras consultas acaso sean ocasionalmente convenientes a fin de que del Presidente de la Asamblea haga un análisis más exhaustivo de la situación política y se lo traslade a todos los consultados con vistas a una decisión más reflexiva.

De otro lado, como las consultas se celebran con los representantes de los Grupos políticos con representación parlamentaria, y no con los Portavoces de los Grupos parlamentarios no habrá que esperar a la constitución de éstos, que podría demorarse.

Añadamos, en fin, que, como señaló en su día A. Bar respecto de la Constitución y acabamos de mencionar, el artículo 18.1 presenta la laguna de no fijar un término a la realización de las consultas, laguna que podría tener importancia en caso de emprenderlas por segunda y tercera vez, puesto que para éstas cuenta el plazo de dos meses, transcurrido el cual se disuelve la Asamblea si no se ha producido la investidura de un candidato.

13 Cfr. Contreras, M.: «El estatuto jurídico-político..., op. cit. (pág. 64). 


\section{Propuesta de candidato}

La propuesta de candidato debe ser el precipitado del juego de las fuerzas parlamentarias, sin que debamos ocuparnos de hipótesis de laboratorio acerca de propuestas fraudulentas - por inviables- buscando la disolución automática de la Asamblea si transcurren, sin investidura, dos meses desde la primera votación. A la Asamblea le sobran recursos para desmontar tal operación y el desgaste sufrido por el Presidente de la Asamblea y por su Grupo político son los mejores elementos disuasorios de dicho comportamiento.

Dispone la Constitución (artículo 152.1) y reiteran el Estatuto madrileño (artículo 16.1), la Ley de Gobierno y Administración (artículo 4) y el Reglamento de la Asamblea (artículo 181) que el candidato propuesto sea Diputado autonómico, requisito que ha sido valorado de forma dispar por la doctrina. Para algunos, entre los que me cuento, no parece inoportuno que así sea en un sistema de Gobierno que, aunque con matices, puede ser calificado de parlamentario ${ }^{14}$. (Por el contrario, como sabemos, la propia Constitución silencia este requisito respecto del Presidente del Gobierno central). A mayor abundamiento, el funcionamiento del sistema como democracia de partidos y la opción de la Ley Electoral de la Comunidad de Madrid, de 1986, a favor de las candidaturas cerradas y bloqueadas, han determinado que los líderes de los partidos encabecen las respectivas candidaturas y personalicen las elecciones. Pero otros autores entienden que, como dijera en sede constituyente el Senador Martín Retortillo, la opción constitucional impide acudir a personalidades políticas no alineadas partidariamente que, en algún caso, podrían servir para desbloquear las negociaciones entre las fuerzas políticas ${ }^{15}$.

Presentación del programa de gobierno y debate

En algunos sistemas parlamentarios, como el británico, el francés, el holandés y el danés, no se requiere que el Parlamento respalde

14 En igual sentido LAFUente Balle, J. Maria: "Elección y control parlamentario del Presidente de la Comunidad Autónoma en el Estatuto para las Islas Baleares", en VV.AA.: Estudios sobre el Estado de Autonomía para las Islas Baleares (Govern Balear. Palma, 1988, pág. 126).

15 Así, Viver I PI-SUNYER, C.: "La figura jurídica...", op. cit. (pág. 65), y BoscH Palanca, $V$. "La figura del Presidente de la Generalitat a l'Estatut d'Autonomia de Catalunya» (RJC núm. xx, Barcelona, 1980, págs. 141-142). 
la formación del Gobierno con una expresa votación de investidura; existe la presunción de que éste goza de la confianza parlamentaria mientras no conste lo contrario por la aprobación de una moción de censura o el rechazo de una cuestión de confianza. Por el contrario, la costumbre constitucional en Bélgica y el texto escrito de la norma suprema en Italia obligan al nuevo Gobierno a presentarse ante las Cámaras para obtener la investidura; no obstante, en ambos casos, el Gobierno entra en funciones sin esperar esa votación de investidura; formación del Gobierno e investidura son, pues, dos procedimientos autónomos, lo que plantea el problema de determinar el alcance del poder y la índole de las competencias de ese Gobierno antes de ser investido, es decir, si tiene plenitud de atribuciones o sólo despacha asuntos de Administración.

La Constitución española resuelve la cuestión de modo diferente: exige la investidura antes de la formación del Gobierno en línea con la Ley Fundamental alemana y con las constituciones monárquicas japonesa y sueca. Así, pues, sin investidura no hay nombramiento de Presidente ni, menos aún, de los demás miembros del Gobierno.

Pues bien, todos los Estatutos de Autonomía, también el madrileño, han seguido en esto a la Constitución. Notemos, sin embargo, que la Constitución y, tras ella, los Estatutos disponen exclusivamente la solicitud de confianza por parte del candidato a la Presidencia, no del nuevo Gobierno, que aún no existe. Incluso lo dan a entender así los propios preceptos (artículo 99.2 constitucional y 18.2 estatutario madrileño) cuando hablan del Gobierno que el candidato pretende formar. En consecuencia, lo que hay propiamente es una investidura de un candidato como Presidente. Es éste quien recibe la confianza para formar Gobierno y cumplir el programa expuesto. Ni siquiera exige el Reglamento del Congreso, así como tampoco del Estatuto ni el Reglamento parlamentario autonómicos, que se anuncie la composición del Gobierno que el candidato quiere formar. A juicio de $A$. Bar, que no comparto del todo, ni siquiera es conveniente, porque - dice- el nombramiento de los restantes miembros del Gobierno es una facultad del Ejecutivo, agotándose el procedimiento parlamentario en la sola investidura del Presidente ${ }^{16}$. Siendo esto cierto, tampoco desvirtúa el sistema parlamentario (antes bien, lo refuerza) el conocimiento del equipo gubernamental proyectado, si es que el candidato no tiene

16 Bar, A.: "Comentario al artículo 22", en Bermejo Vera, J. (Dir.): Op. cit. (págs. 248-249). 
dificultades añadidas para definirlo por su precaria mayoría parlamentaria.

Pero la investidura es posterior a la exposición de un programa político. Hay, por ende, que suponer que, al menos en parte, el candidato es investido para realizar dicho programa. A este entendimiento contribuye también el precepto reglamentario, que dispone un debate sobre el programa, previo a la votación.

La doctrina, o un sector de ella, cree ver por eso una suerte de compromiso político que liga al Presidente $y$ al Gobierno con el Parlamento y, a través de éste, con el cuerpo electoral: una especie de contrato de legislatura. A mí no me parece jurídicamente fundamentada la existencia de una obligación del Presidente de revalidar la confianza parlamentaria mediante el planteamiento de una cuestión de confianza en caso de introducir cambios sustanciales en el programa de Gobierno ${ }^{17}$; sin embargo, si no lo hace, proporcionará una buena ocasión a la oposición para intentar restarle credibilidad política. $Y$, por otra parte, también la Asamblea (es decir, la mayoria favorable a la investidura) queda políticamente comprometida en el envite y deberá respaldar las iniciativas legislativas del Gobierno en el cumplimiento del programa, lo que suele estar garantizado a través de la disciplina de voto de los Diputados.

\section{Votación de investidura}

Finalizado el debate, se procede a la votación. El artículo 18.3 del Estatuto - lo mismo que el 99.3 de la Constitución- exige la mayoría absoluta de los miembros de la Asamblea para considerar otorgada su inicial confianza al candidato, es decir, el voto favorable de más de la mitad de los Diputados. De no alcanzarla, éste se someterá a una nueva votación cuarenta y ocho horas después, en la que basta la mayoría simple o, lo que es igual, más votos favorables que desfavorables, siempre que esté presente la mayoría de la Cámara. No es necesario un nuevo debate antes de esta segunda votación. Como libre y expedita está la vía de la retirada del candidato $^{18}$, con lo que la segunda vota-

17 A favor de la renovación de la confianza, BAR, A.: Op. y Jug. cit. en la nota anterior. VIVER i Pi-SUNYER, C.: "La figura jurídica...", op. cit. (págs. 57 y 63-64), destaca ese ligamen del Presidente con el Parlamento, mejor con la mayoría parlamentaria, pero no defiende la necesaria renovación de la confianza en tales casos.

18 Bar, A.: "Comentario al artículo 22", op. cit. (pág. 250). 
ción no tendría lugar y se procedería, por parte del Presidente de la Asamblea, a evacuar nuevas consultas.

Si, como parece improbable (puesto que para algo habrán servido las consultas previas), tampoco confiere su confianza la Asamblea en la segunda votación, deberán tramitarse sucesivas propuestas, en las que ha de seguirse el mismo procedimiento, comenzando por nuevas consultas. $M$. Contreras estima que las nuevas propuestas exigen nuevos candidatos ${ }^{19}$, en tanto que $A$. Bar interpreta que para que la propuesta sea nueva basta con que se hagan correcciones en el programa ${ }^{20}$ (probablemente pactadas con algún Grupo parlamentario dispuesto a votar favorablemente) ${ }^{21}$. A mi juicio, lo usual será un cambio de candidato tras el fracaso anterior, ya que la denominada ualquimia parlamentaria" tiene límites y no da para todo, además de que es contraproducente el empecinamiento en las personas, pero no está exigido así jurídicamente.

Finalmente, si transcurren dos meses desde la primera votación y ningún candidato ha obtenido la confianza parlamentaria, la Asamblea queda disuelta, convocándose de inmediato nuevas elecciones. En esto, el Estatuto madrileño también sigue el modelo de la Constitución. La única diferencia estriba en el acortamiento del mandato de la nueva Asamblea Legislativa autonómica, el cual finaliza cuando le habría correspondido a la disuelta. Esta es la solución adoptada en la mayoría de las Comunidades Autónomas y tiene la opinión favorable del sector mayoritario de la doctrina, frente a la opción minoritaria -en el Derecho positivo y en la doctrina - de la investidura automática de un candidato, fórmula que, a mi juicio, ha rendido resultados muy negativos en Andalucía y en Navarra, permaneciendo todavía inédita en CastillaLa Mancha22.

19 Contreras, M.: «El estatuto jurídico-político...», op. cit. (págs. 65-66).

20 BAR, A.: "Comentario al artículo 22", op. cit. (pág. 250).

21 Sobre los diferentes sistemas de investidura en el Derecho autonómico comparado, cfr. Lafuente Balle, J. María: “Elección y control...», op. cit. (págs. 128129).

22 Se han pronunciado en contra de la investidura automática, entre otros, Montero, J. R. y Morales, J. María: “El sistema parlamentario...», op. cit. (págs. 573575); Rulz-Rico RuIz, G.: Op. cit. (págs. 255-257); Rulz Robledo, A.: Comunidad Autónoma de Andalucía (Parlamento de Andalucía. Sevilla, 1988, pág. 152); y VIDAL PraDo, C.: "Un problema pendiente: la modificación del sistema de elección del Presidente de la Diputación en el Amejoramiento del Fuero de Navarra" (RCG núm. 38. Madrid, 1996). A favor, REVENGA, M.: "Notas sobre el procedimiento...", op. cit. (pág. 628). 
La disolución de las Cámaras es un acto reglado, obligatorio, en el que no cabe margen alguno de discrecionalidad. La Asamblea (como, en su caso, las Cortes Generales) son "penalizadas" de este modo, si puede hablarse en estos términos, por su incapacidad para investir a un Presidente del Gobierno.

La votación, según el Reglamento de la Asamblea (artículo 125.2) será pública por llamamiento, es decir, cada Diputado vota oralmente desde su escaño al ser nombrado por el Secretario de la Cámara encargado de ello. De este modo se favorece, de hecho, la disciplina de los Grupos parlamentarios sobre los Diputados.

\section{Nombramiento regio del Presidente y toma de posesión}

Otorgada la confianza a un candidato, el Presidente de la Asamblea lo comunica al Rey para su nombramiento como Presidente de la Comunidad de Madrid. Este nombramiento es un acto debido en el que el Rey se limita a formalizar como acto estatal una decisión de Gobierno de la Nación y publicado en el "Boletín Oficial de la Comunidad de Madrid" y en el "Boletín Oficial del Estado", según dispone el artículo 4 de la Ley del Gobierno y Administración de esta Comunidad. Una vez nombrado, toma posesión de su cargo ante la Mesa de la Asamblea (artículo 184.1 del Reglamento de ésta).

Fue discutido en su día si el refrendo debía corresponder al Presidente del Parlamento autonómico, argumentando su mejor situación institucional para certificar la corrección del acto y hacerse responsable de él. A mi juicio, este argumento apunta a una solución que podría ser estimada como jurídicamente correcta a poco que se interpretara analógicamente el artículo 64.1. de la Constitución. El Tribunal Constitucional, por el contrario, hizo una interpretación literal del mencionado precepto y resolvió a favor del refrendo del Presidente del Gobierno central23.

No dice el Estatuto, ni la Ley de Gobierno y Administración, ni el Reglamento de la Asamblea, que el Presidente deba prestar juramento o promesa de acatamiento de la Constitución, cuestión que, sin embargo, aparece ya resuelta, ya que el Presidente ha tenido que prestar tal juramento o promesa por su condición de parlamentario (artículo 12.1.c del Reglamento de la Asamblea de Madrid). 
Nombramiento y cese de los restantes miembros del Gobierno

El artículo 22.2 del Estatuto es un ejemplo paradigmático de defectuosa técnica legislativa, lo mismo en su redacción de 1983 (entonces figuraba como artículo 21.2 y 3) que en la actual de 1998. Pues, efectivamente, dice en su inciso primero que el Gobierno está compuesto (mejor sería decir integrado) por el Presidente, el o los Vicepresidentes, en su caso, y los Consejeros; para añadir en el segundo que los miembros del Gobierno serán nombrados y cesados por el Presidente.

Resulta meridiano que el Presidente es miembro del Gobierno y que no se nombra ni se cesa a sí mismo, sino mediante el procedimiento enunciado más arriba y sobre el que volveremos enseguida. Con todo, la intelección correcta del precepto es bien sencilla, basta con entender que "los miembros del Gobierno" son «los demás", aparte del Presidente. Lo dice mejor el artículo 17.1 estatutario, conforme al cual, el Presidente "designa y separa a los Vicepresidentes y Consejeros". Aquí sí se dice lo que se quiere decir, pero al precio de duplicar preceptos innecesariamente.

Lo que a la postre interesa a este comentario es destacar la posición inequívocamente superior del Presidente respecto de "los demás" miembros del Gobierno, que deben su puesto y su permanencia en él a la confianza de aquél. Habremos de volver sobre ello en un posterior epígrafe.

\section{RASGOS GENERALES DEL ESTATUTO JURÍDICO DEL PRESIDENTE}

\section{Status y funciones}

Como dice el artículo 152.1 de la Constitución y reitera el artículo 17 del Estatuto, el Presidente de la Comunidad ostenta la suprema representación de la Comunidad Autónoma y la ordinaria del Estado en la misma. Añade el precepto constitucional que le corresponde la dirección del Consejo de Gobierno, y el Estatuto, después de reducir el sintagma "Consejo de Gobierno" por el mas simple de "Gobierno", precisa que el Presidente "preside y dirige" su actividad, lo que en verdad no es más que sumar una evidencia a la dicción constitucional, pues evidente es que el Presidente preside. Por fin, el precepto estatutario concluye con otra función más del Presidente: coordina la Administración. 
La suprema representación de la Comunidad Autónoma debe ser entendida en sus proyecciones interna y externa, esto es, dentro v fuera de la Comunidad. En cambio, la representación del Estado es una función ejercible sólo dentro de la propia Comunidad, puesto que de un lado, en las demás Comunidades Autónomas esta representación corresponde a sus respectivos Presidentes, $y$, de otro, la representación del Estado en las relaciones internacionales es una competencia inasumible por las Comunidades Autónomas, puesto que corresponde al poder central (concretamente al Gobierno, que el que, de acuerdo con el artículo 97 constitucional, dirige la política exterior) y, en su grado máximo, al Rey (artículo 56 del propio texto fundamental).

Por esa representación de la Comunidad y del Estado en la misma le corresponde - $y$ así lo dice el artículo 40.1 del Estatuto- la promulgación de las Leyes autonómicas en nombre del Rey. (Como es sabido, estas Leyes no son sancionadas). Pero la Ley de Gobierno y Administración diferencia los dos tipos de representación que en él convergen.

a) La mencionada facultad de promulgación de las Leyes autonómicas le corresponde - dice la Ley-por ser representante del Estado en la Comunidad, añadiendo otro tanto respecto de los Decretos legislativos. También le corresponde mantener relaciones con la Delegación del Gobierno (central) "a los efectos de una mejor coordinación de las actividades del Estado y las de la Comunidad de Madrid" (artículo 8).

b) Como representante supremo de ésta firma los Convenios y Acuerdos de cooperación con otras Comunidades Autónomas y convoca las elecciones a la Asamblea de Madrid en los términos del artículo 11 del Estatuto (artículo 7).

\section{Dirección de la actividad del Gobierno}

Por lo que se refiere a esta otra función, el mimetismo del Estatuto respecto de la Constitución es evidente: el Gobierno es el órgano de dirección de la política, y el Presidente el órgano de dirección del Gobierno (artículos 97 y 98.2 de la Constitución y 20.1 y 17.1 del Estatuto). 
Dirigir al órgano de dirección de la política es tanto como llevar la dirección suprema de ésta o, por ahorrar adjetivos, dirigirla lisa y llanamente, a pesar de la dicción literal de los artículos 97 constitucional y 20.1 estatutario. Tanto más cuanto que, como vimos anteriormente, el Presidente designa y separa a los restantes miembros del Gobierno autonómico.

Y, en efecto, la Ley de Gobierno y Administración no deja de extraer conclusiones al respecto, puesto que su artículo 9 dispone que, en su condición de Presidente del Consejo de Gobierno, le corresponden, entre otras atribuciones:

a) Establecer las directrices generales de la acción de Gobierno.

b) Convocar las reuniones del Consejo y de sus Comisiones Delegadas, fijando el orden del día.

c) Firmar los Decretos y ordenar su publicación.

d) Asegurar la coordinación entre las distintas Consejerías y resolver los conflictos de competencias entre ellas.

e) Coordinar el programa legislativo del Consejo de Gobierno.

f) Solicitar, previo Acuerdo del Consejo de Gobierno, una Sesión extraordinaria de la Asamblea.

g) Plantear ante la Asamblea una cuestión de confianza. Esta cuestión, según prescribe el artículo 19.1 del Estatuto, debe versar sobre su programa de Gobierno o sobre una declaración de política general.

También puede -aunque la citada ley lo silencia en el elenco de funciones de su artículo 9- disolver la Asamblea antes del término natural de la legislatura (artículo 21 del Estatuto).

De igual modo, la Asamblea puede exigir su responsabilidad política (o la de su Gobierno) mediante una moción de censura (artículo 20 id.), lo que también es expresivo de su posición preeminente en el Gobierno autonómico. Estos tres últimos institutos serán comentados en epígrafes sub-
siguientes. Estos tres últimos institutos serán comentados en epígrafes sub-
siguientes. 


\section{Naturaleza del órgano}

Ciertamente, este diseño institucional no es el del clásico poder moderador o neutral ${ }^{24}$. No deben llevarnos a esa falsa idea sus funciones representativas, pues, junto a ellas y dándole todo el color político imaginable, el Presidente dirige el Consejo de Gobierno. Esta función de dirección política, unida a su condición de parlamentario, que ha competido en las urnas dentro de una candidatura partidaria, y su forma de elección con un debate sobre su programa, difumina la apariencia que pudiera tener en algunos pasajes del Ordenamiento jurídicopolítico autonómico de un status similar al de un Jefe de Estado en un sistema parlamentario de Gobierno.

En correspondencia con sus funciones políticas de gran alcance y nivel decisorio, es responsable ante la Asamblea y habrá de soportar la oposición a su política por parte de Grupos políticos adversarios.

Pero no es que haya dos cargos - Presidente de la Comunidad y Presidente del Gobierno de dicha Comunidad-desempeñados por la misma persona, sino que el cargo de Presidente de la Comunidad comporta la función de dirección del Gobierno y coordinación de la Administración junto con las representativas. Un solo órgano con funciones diversificadas A. Ruiz Robledo, refiriéndose a la Comunidad Autónoma de Andalucía, entiende que "ésa es la naturaleza exacta del Presidente de la Junta: Jefe del Ejecutivo, sin perjuicios de que desempeñe otras funciones atípicas de esta figura en los subsistemas de Gobierno parlamentario... que no llegan a transformar su naturaleza. Estas funciones se justifican por un principio de economía: no crear un nuevo órgano...". Esa es la idea fundamental: un solo órgano con doble función. Acaso cupiera invertir la definición: Presidente de la Comunidad que también dirige al Gobierno. Pero el resultado es el mismo.

\section{Delegación de funciones presidenciales}

De manera algo enigmática dice al artículo 17.2 del Estatuto que el Presidente puede delegar "funciones ejecutivas y de representación propias" en otros miembros del Gobierno. ¿Sólo las ejecutivas y de representación? ¿Excluye el precepto comentado la función de dirección política?

24 Cfr. Martinez Sospedra, M.: Op. cit. (pág. 235) y RiBAS, A.: Op. cit. (pág. 196). 
Hay apoyo para dicha interpretación si entendemos que la dirección política es inherente a la Presidencia del Gobierno y, como tal, indelegable. Así es como lo ha interpretado la Ley de Gobierno, que en su artículo 10.2 declara idelegables, entre otras, la facultad de nombrar y separar a los demás miembros del Consejo de Gobierno -excepción absolutamente obvia- y las descritas en el anterior apartado de este estudio bajo las letras $a, d, f$ y g, todas ellas facultades de dirección política inherentes a dicha dirección.

\section{Régimen de incompatibilidades}

El artículo 23.1 del Estatuto madrileño parece establecer el mismo régimen de incompatibilidades para todos los miembros del Gobierno, incluido el Presidente: no podrán ejercer otras actividades laborales, profesionales o empresariales que las derivadas del ejercicio de su cargo.

Pero inmediatamente remite a la Ley (autonómica) la regulación de dicho régimen, con el pie forzado, eso sí, del criterio antes expuesto. Esta Ley data del 13 de diciembre de 1983 y es la ya varias veces mencionada Ley de Gobierno y Administración de la Comunidad de Madrid, modificada media docena de veces, la última por Ley 28/1997, de 26 de diciembre. Esta Ley podría haber establecido algunas diferencias respetando los mínimos estatutarios antes mencionados, pero no ha sido así, sino que, por el contrario, el artículo 30 remite el régimen de incompatibilidades de los Consejeros al fijado por el artículo 6 para el Presidente, y éste dice, algo más prolijamente, lo mismo que el artículo 23.1 del Estatuto, con la única adición -obligada, por lo que sabemos- del cargo de Diputado de la Asamblea, que es declarado compatible con el de Presidente de la Comunidad y, por ende, también con del de Consejero.

\section{Fuero penal y civil}

El artículo 25.1 del Estatuto residencia en la Sala de lo Penal del Tribunal Supremo la responsabilidad penal de todos los miembros del Gobierno, indistintamente, lo mismo que hace la Constitución respecto de los miembros del Gobierno central. Hace el precepto estatutario una salvedad con los Vicepresidentes y Consejeros que no reza con el Presidente, a saber: para los delitos cometidos en el ámbito de la Comunidad les será exigible la responsabilidad ante el Tribunal de Justicia de Madrid. 
Y lo mismo - con idéntica salvedad- hay que decir de la responsabilidad civil: para el Presidente, la Sala de lo Civil del Tribunal Supremo; para los demás miembros del Gobierno, la de éste o la del Tribunal Superior de Madrid, según los casos.

\section{Ausencias, incapacidad y cese. Presidente interino y Presidente en funciones}

a) Las ausencias temporales del Presidente superiores a un mes precisan la previa autorización de la Asamblea (artículo 12 de la Ley de Gobierno).

b) El Consejo de Gobierno puede apreciar, por acuerdo de 4/5 de sus miembros, que el Presidente se encuentra imposibilitado física o mentalmente de forma transitoria para el desempeño de sus funciones, en cuyo caso lo comunicará al Presidente de la Asamblea con expresión de los motivos y justificantes pertinentes, incluyendo en dicha comunicación el nombre del Presidente interino. El Presidente de la Asamblea convocará al Pleno, el cual tiene atribuciones para revocar el mencionado acuerdo por mayoría absoluta. Pero, de no hacerlo así, el acuerdo gubernamental se publica en el «Boletín Oficial de la Comunidad de Madrid" y en el "Boletín Oficial del Estado" y será ejecutivo (artículo 13 de la Ley de Gobierno).

c) Ejercerá interinamente la Presidencia el Vicepresidente, si lo hay; el Vicepresidente primero, si hay varios; o, en caso negativo, el Consejero titular del Departamento Primero en orden de prelación 25.

El Presidente interino ejerce todas las funciones presidenciales, salvo las de definir el programa de Gobierno y designar y separar los restantes miembros del Consejo de Gobierno. La interinidad no excederá de dos meses, ampliables a otros dos previo Acuerdo de la asamblea, y cesará cuando el Presidente titular recupere sus facultades, lo comunique al Consejo de gobierno y éste así lo aprecie por 4/5 de sus miembros, comunicándolo seguidamente a la Asamblea y publicándolo en los dos Boletines antes citados (artículos 14 y 15 de la Ley de Gobierno).

d) El Presidente cesa por renovación de la Asamblea, por pérdida de la confianza de ésta, por dimisión y por incapacidad permanente (artículos 14 y 15 de la Ley de Gobierno). Puede apreciarse inca- 
pacidad permanente transcurridos cuatro meses de incapacidad transitoria sin que se haya logrado la rehabilitación, o antes incluso si así lo declara la Asamblea por mayoría absoluta a propuesta del Consejo de Gobierno alcanzado por mayoría de 4/5. La Ley añade, como es usual $\checkmark$ disparatado, que también cesa por fallecimiento, lo que de ningún modo puede entenderse jurídicamente como un cese, sino como extinción física del sujeto. Cesa también por causas penales, a saber: por sentencia condenatoria firme que lo inhabilite para el desempeño de empleo o cargo público, o que simplemente lo suspenda. $Y$, en fin, igualmente cesa en el cargo si pierde la condición de Diputado o por incompatibilidad sobrevenida no subsanada ${ }^{26}$.

EI Presidente cesante, salvo si lo es por incapacidad permanente (el supuesto de fallecimiento no requiere comentario alguno), continuará en funciones hasta la toma de posesión de su sucesor, no pudiendo mientras tanto plantear una cuestión de confianza ni ser censurado (artículo 17.2 de la Ley de Gobierno). Obviamente, aunque la mencionada Ley lo silencia, tampoco puede continuar en funciones si el cese se produce por causa penal, por pérdida de la condición de Diputado o por incompatibilidad sobrevenida, porque en estos casos pierde de raíz las condiciones jurídicas para ostentar el cargo.

\section{RESPONSABILIDAD POLÍTICA}

El artículo 152.1 de nuestra norma fundamental dispone que el Presidente autonómico y los miembros del Consejo de Gobierno son políticamente responsables ante la Asamblea. Esta declaración es recogida por el Estatuto de Autonomía de Madrid en dos preceptos separados que requieren una interpretación conjunta y armónica.

a) Por una parte, el artículo $\mathbf{1 7 . 3}$ dice que el Presidente es políticamente responsable ante la Asamblea.

b) Por otra, el 23.2 afirma igual responsabilidad del Gobierno y añade que responde "de forma solidaria".

c) Pero el inciso final del precepto últimamente citado aclara a continuación: «sin perjuicio de la responsabilidad directa de cada Consejero por su gestión".

Anotemos: 
1. Los dos incisos del mencionado artículo 23.2 estatutario no son sino traslaciones de lo que el artículo 108 de la Constitución y el inciso final del 98.2, también constitucional, disponen para el Gobierno central. La equivocidad del texto fundamental, por tanto, se reproduce en el Estatuto madrileño, puesto que se afirma la responsabilidad individual de los miembros del Gobierno, pero, al mismo tiempo, se asevera que la responsabilidad de éste es solidaria. Me he pronunciado sobre este problema en otro lugar, al que remito 27.

2. Pero los preceptos estatutarios afirman igualmente la responsabilidad política del Presidente, cosa que no hace la Constitución. Tal afirmación est totalmente innecesaria dado que el Presidente es miembro del Gobierno.

3. $Y$, en tercer lugar, por olvido del legislador estatuyente, el/los Vicepresidente(s) no es/son mencionado(s) como individualmente responsable(s), lo que parece hacerlo(s) de mejor condición que a los demás miembros del Gobierno, incluido el Presidente. La laguna es tan disparatada que resulta fácilmente superable por vía interpretativa el estatuto del Vicepresidente se asimila al de los Consejeros de Gobierno.

Por lo que interesa a este trabajo, hemos de indicar que la responsabilidad del Presidente no es diferente de la solidaria del Gobierno. No sólo porque aquél es miembro de éste, como hemos adelantado, sino porque el cese y la dimisión del Presidente comporta la del Gobierno, según establece el artículo 24.1 del Estatuto de manera casi exactamente literal al artículo 101 de nuestra Ley de Leyes. O lo que es lo mismo: no se puede exigir la responsabilidad del Presidente sin involucrar en ello a todo el Gobierno; y viceversa: tampoco se puede exigir la responsabilidad política solidaria del Gobierno haciendo abstracción del Presidente, que es su cabeza28.

Pues bien, los dos institutos en que se cifra la responsabilidad política del Ejecutivo en un sistema parlamentario son la moción de censura y la cuestión de confianza. Como el sistema de Gobierno de la

27 Torres del Moral, A.: Principios de Derecho Constitucional Español (Publicaciones de la Facultad de Derecho de la Universidad Complutense, 4. ${ }^{a}$ ed. Madrid, 1998, págs. 651-656).

28 Cfr. Lafuente Balle, J. María: "Elección y control...», op. cit. (págs. 131132), sobre las diversas opciones legislativas (regulación conjunta o separada de la responsabilidad del Presidente y del Consejo de Gobierno, etc.) en el Derecho autonómico comparado. 
Comunidad madrileña es, en términos generales, parlamentario, uno $y$ otro institutos se dan cita en su Estatuto de autonomía. Los comentamos a continuación con brevedad $y$ en perspectiva exclusivamente presidencial. Veamos:

a) La cuestión de confianza es planteada por el Presidente, previa deliberación del Gobierno. Tanto en esto como en los demás pormenores de la institución el Estatuto de Madrid (artículo 19) se ajusta a los dispuesto por la Constitución (artículos 112 y 114): objeto de la cuestión, mayoría exigida para entenderla otorgada, dimisión obligatoria en caso contrario, etc. Está regulada en detalle por los artículos 185 y 186 del Reglamento de la Asamblea.

Lo que importa retener aquí es el protagonismo del Presidente, que no está obligado a seguir el parecer del Gobierno, sino tan sólo a someter su decisión a la previa deliberación de éste.

b) También en la regulación de la moción de censura sigue el Estatuto (artículo 20) a la Constitución (artículos 113 y 114.2):

1. Exigencia de un porcentaje elevado de suscriptores de la moción (15 por ciento el Estatuto, frente al 10 por ciento la Constitución).

2. Exigencia de mayoría absoluta para aprobar («adoptar») la moción.

3. Plazo de cinco días entre la presentación de la moción y su votación.

4. Penalización a los suscriptores si la moción no fuese aprobada.

5. Cese del Presidente y de su Gobierno en caso de aprobación de la moción e investidura y nombramiento del candidato incluido en ella.

Todo lo cual es igualmente regulado en detalle por los artículos 187 a 190 del Reglamento de la Asamblea Legislativa.

No hay, pues, novedad en nada de lo anotado y cabe hacer de este modelo de responsabilidad las mismas consideraciones que hemos hecho en otro lugar al instituto constitucional ${ }^{29}$.

29 Torres del Moral, A.: Op. cit. (págs. 662-668). 
Pero si cabe insistir en que este tipo de moción de censura enfrenta al Presidente censurado - arropado por su Gobierno-y el candidato propuesto en moción, subrayándose con ello una vez más la posición jurídica cualitativamente distinta del Presidente en relación con el resto del Gobierno: la censura del primero se combina con la investidura del segundo, de manera que la confianza de la Asamblea, como en el caso de la investidura, queda conferida, en su caso, al nuevo Presidente, tras lo cual éste procede a nombrar a su equipo de Gobierno.

En fin, como apunta C. Viver y es quizás innecesario advertir, el Presidente es políticamente responsable incluso cuando delega sus funciones en otro miembro del Gobierno ${ }^{30}$.

(Por razones tantas veces esgrimidas no comentaré la laguna jurídica existente en el Ordenamiento madrileño, como también en el constitucional y en el autonómico en general, salvo en el País Vasco, al no regularse el procedimiento de responsabilización política de los restantes miembros del Gobierno individualmente conside(rados) ${ }^{31}$.

\section{DISOLUCIÓN DE LA ASAMBLEA POR EL PRESIDENTE DE LA COMUNIDAD}

La reforma del Estatuto madrileño aprobada por Ley Orgánica 5/1998, de 7 de julio, ha introducido un nuevo artículo, el actual 21, que regula la disolución anticipada de la Asamblea. $Y$ de nuevo lo hace de modo similar al de la Constitución (artículo 115):

1. La decisión corresponde al Presidente. El requisito de la previa deliberación del Gobierno es razonable, pero carente de fuerza vinculante.

2. El decreto de disolución contendrá la convocatoria de nuevas elecciones.

3. Se establecen límites temporales para la disolución.

30 Viver i Pi-Sunyer, C.: "La figura jurídica...", op. cit. (pág. 77).

31 Sálz Arnálz, A.: La forma de Gobierno de la Comunidad Autónoma Vasca (IVAP, Oñati, 1988, págs. 100-102). 
4. El mandato de la nueva Asamblea está limitada por el término de la legislatura de origen.

De nuevo, lo que debemos resaltar es el protagonismo del Presidente como interlocutor de la Asamblea muy por encima del Gobierno como órgano colegiado. $Y$ como el Presidente es previsiblemente el líder del partido gobernante en la Comunidad (otra cosa habría que decir en caso de Gobierno de coalición), la disolución de la Asamblea es un arma política en su mano para convocar elecciones autonómicas en el momento que entienda más favorable para su partido.

Según se desprende de cuanto dijimos en el epígrafe segundo, la incorporación de este instituto de la disolución parlamentaria en los Estatutos de Autonomía, no sólo en el madrileño, elimina uno de los obstáculos más frecuentemente esgrimidos - con razón- para la calificación de los sistemas autonómicos de gobierno como parlamentarios. Ahora, la asimilación al sistema constitucionalmente establecido para el Gobierno central es mayor, quedando tan sólo la diferencia del acortamiento del mandato de la nueva Asamblea, como también anotamos en su momento.

\section{CONCLUSIÓN: ¿LIDERAZGO DEL PRESIDENTE O COLEGIALIDAD DEL GOBIERNO?}

Se discutió en un primer momento acerca de la calificación adecuada de los sistemas de Gobierno instaurados en las Comunidades Autónomas, si parlamentarios o presidenciales, o incluso si diferían de unas Comunidades a otras. Hoy parece haber remitido la polémica -que, ciertamente, nunca fue objeto de demasiada atención por parte de los constitucionalistas - ante la evidencia de que la respuesta depende siempre más de los datos sociopolíticos, concretamente del sistema de partidos, que de la regulación estatutaria y/o legal de las relaciones entre los dos poderes clásicos: el Ejecutivo y el Legislativo.

Con todo, se puede apreciar alguna diferencia ocasionada por el dato jurídico en aquellas Comunidades en las que el Presidente puede ser automáticamente investido si el Parlamento no dirime la cuestión. Pues, en efecto, la confianza parlamentaria, por costosa que sea une a dichos poderes en una suerte común, o poco menos, respaldando el parlamento la política gubernamental en normalidad de circunstancias, en tanto que la investidura automática significa, de entrada, que no existe tal relación fiduciaria y que la oposición, aunque no logre acordar un candidato alternativo a la Presidencia del Gobierno para in- 
corporarlo a una moción de censura (o, previamente, para votarlo en la investidura), sin embargo sí puede torpedear todas las iniciativas gubernamentales, dificultando hasta límites extremos -o incluso impidiendo- la gobernación de la Comunidad. Ejemplos ha habido ${ }^{32}$.

En estos supuestos apenas merece la pena plantearse la cuestión de si la dirección política responde al principio de liderazgo presidencial o al de colegialidad gubernamental, pues, en puridad, no hay ni lo uno ni lo otro. Pero en los demás casos, que son mayoría, bien por una regulación estatutaria más ortodoxa, bien por gozar un partido de mayoría absoluta, sí cabe reflexionar sobre la disyuntiva enunciada.

Tal es lo que acontece en la Comunidad Autónoma de Madrid. Situados en ella y recordando lo dicho en epígrafes anteriores, puede concluirse que, por lo que se refiere a la posición que adopta el Estatuto, prima el principio de liderazgo sobre el de la colegialidad y así lo hemos venido resaltando. El fundamento de tal conclusión es:

a) La investidura la recibe el candidato a la Presidencia, no el Gobierno, que, como tal, no existe todavía, o está meramente en funciones.

b) Los restantes miembros del Gobierno son nombrados y cesados por el Presidente. Luego deben el acceso a su puesto y la permanencia en él a la exclusiva y discrecional confianza de éste.

c) Pese a lo dicho en el artículo 21.2, primer inciso, acerca de la "responsabilidad directa de cada Consejero por su gestión", lo cierto es que la responsabilidad política instrumentada por el propio Estatuto es la solidaria del Gobierno ante la Asamblea, según prescribe el mismo precepto citado en el primer inciso. Esto podría argüir a favor del principio de colegialidad, pero no resulta ser asi porque:

1. Como todos y cada uno de los Consejeros del Gobierno dependen estrictamente de la confianza del Presidente, no hay ni puede haber solidaridad gubernamental antipresidencial, ni siquiera al margen del Presidente.

2. El propio Gobierno se solidariza ex statuto con el Presidente cuando la Asamblea exige la responsabilidad política de éste mediante una moción de censura y cuando es el propio Presidente el que, incluso contra el parecer de los demás miembros del Gobierno, plantea a la Asamblea una cuestión de confianza. 
El largo elenco de atribuciones del Consejo de Gobierno contenido en el artículo 21 de la Ley de Gobierno no desvirtuará lo dicho, puesto que, incluso en las funciones más trascendentes, como aprobar el proyecto del Presupuesto anual de la Comunidad, aprobar los demás Proyectos de Ley, dictar Decretos Legislativos, acordar la interposición de recursos de inconstitucionalidad y el planteamiento de conflictos de competencia, etc., el Consejo de Gobierno no hace sino seguir la política del Presidente ${ }^{33}$. Por eso algún autor, refiriéndose a otra Comunidad Autónoma, ha dicho que el Presidente es el supremo órgano político y el Consejo de Gobierno el supremo órgano administrativo ${ }^{34}$. Este esquemático aserto podría ser matizado a favor, todavía más, del Presidente, al menos en la Comunidad de Madrid, cuyo Estatuto, artículo 17, confiere al Presidente la coordinación de la Administración.

Ahora bien, como decía Paul Verlaine, la verdad de las cosas reside en sus matices. Y los matices, en el problema examinado, vienen proporcionados por los datos de la realidad política, en concreto por los resultados en las urnas y por el sistema de partidos ${ }^{35}$.

33 En general, la doctrina ha resalto la prevalencia del principio de liderazgo sobre el de colegialidad, aunque no faltan los matices. Así, por ejemplo, referido a Cataluña, Viver, C.: "La figura jurídica...", op. cit. (págs. 97-103), se inclina más bien por la consideración del Presidente en el seno del colegio gubernamental; y respecto de la Comunidad balear, RiBAs, A.: Op. cit. (págs, 196 y 208), habla de primacia y de supremacía del Presidente, pero niega su superior jerarquía por entender que necesita del Gobierno en su actuación.

En relación con el País Vasco, Garcia Herrera, M. A.: «La coordinación del Presidente del Gobierno", en VV.AA.: El Gobierno en la Constitución española y en los Estatutos de Autonomía, estima que la función presidencial de dirección es intermedia entre la paridad y la supremacía. Martinez Sospedra, M.: Op. cit., después de resaltar la preeminencia del Presidente valenciano sobre el Consejo, de manera que, dice, no hay Consejo sin Presidente (págs. 219-220), aduce que en el ejercicio de la función ejecutiva hay más colegialidad (págs. 233-234).

34 Fanlo, A.: "Comentario al artículo 23", en Bermejo Vera, J., op. cit. (pág. 258).

35 Afirman la preeminencia del Presidente, pero advierten de que ésta debe verse confirmada en la práctica, en la que "mandan" los datos sociopolíticos, entre otros, Cámara, G.: "El Poder Ejecutivo...", op. cit. (págs. 14-16); Lucas Murillo de la Cueva, E.: El Lehendakari (IVAP, Oñati, 1990, págs. 29-34);Revenga, M.: "Notas..", op. cit. (pág. 610), pero añade que la Ley del Gobierno ha acentuado la preeminencia del Lehendakari; y CONTRERAS, M.: "El estatuto jurídicopolíitco...n, op. cit. (pág. 66), termina preguntándose si el programa de Gobierno es el del presidente, para responder que es en la práctica donde tiene que precisarse. 
Como he escrito en otro lugar ${ }^{36}$, el liderazgo presidencial se acentúa cuando:

a) El partido del Gobierno goza de mayoría absoluta en el Parlamento.

b) Está muy cohesionado.

c) El Presidente es líder indiscutido de dicho partido.

$Y$ desciende cuando falta alguno de dichos elementos, hasta disiparse por completo si faltan todos.

Trasladando esta pautas de análisis a la Comunidad de Madrid, observamos que en unos períodos ha habido -o hay-Gobierno con mayoría absoluta de un partido y en otros no. En efecto:

1. Hubo Gobierno con mayoría absoluta de un partido en las dos primeras legislaturas (1983-1987-1991), en la cuarta (1995-1999) y la hay en la quinta (1999-2001). En aquéllas, con Gobierno del Partido Socialista, y en éstas, del Partido Popular. En las cuatro el partido del Gobierno estaba o está lo bastante cohesionado como para no presentar fisuras importantes.

2. En la tercera legislatura (1991-1995) hubo Gobierno de coalición PSOE-IU, al no tener el primero mayoría absoluta.

3. Lógicamente, por escaso que sea el liderazgo del Presidente sobre el Gobierno en el primer supuesto, siempre será mayor (rebus sic stantibus) que en el segundo, puesto que en el seno de un Gobierno de coalición hay miembros de disciplina partidaria distinta con los que hay que acordar las líneas fundamentales de la dirección política.

4. Ya es menos tangible el elemento del liderazgo intrapartidario del Presidente, puesto que por hipótesis y por muy descentralizada que sea la estructura territorial del partido (que no lo es tanto ni en el caso del PSOE ni en el del PP), el liderazgo máximo y acaso indiscutido del partido es el nacional, no uno regional. Ser líder en la región es mucho, pero no lo es todo. $Y$ menos en Madrid, donde ha de coexistir con el o los líderes nacionales. Exagerando el diagnóstico, podría de-

36 Torres del Moral, A.: "Modelo de Gobierno de la Constitución Española", en Álvarez Conde, E. (Coord.): Administraciones Públicas y Constitución. Reflexiones sobre el XX aniversario de la Constitución española de 1978 (Instituto Nacional de Administración Pública, Madrid, 1998, págs. 413-427). Cfr. en el mismo sentido mi trabajo "El Estado español de partidos» (Revista del Centro de Estudios Constitucionales núm. 8, enero-abril 1991, págs. 111-112) y mis Principios de Derecho Constitucional Español, op. cit. (pág. 636). 
cirse que en esta Comunidad, los líderes de los dos principales partidos (que son de implantación nacional y los únicos que pueden formar Gobierno en Madrid, tanto central como regional) son muy dependientes de las Ejecutivas nacionales, que los mantienen como tales sólo mientras lo crean conveniente.

Supuesto lo anterior, el mencionado elemento del liderazgo queda muy relativizado y, con él, todo el análisis anterior. Habría que formular dicho elemento de otra manera, a saber: el apoyo de la Ejecutiva nacional del partido al Presidente del Gobierno regional como líder en la Comunidad Autónoma. Y, corregido en estos términos, no puede decirse que los dos Presidentes habidos hasta ahora hayan gozado de un respaldo irrestricto de sus partidos respectivos, y ni siquiera de una relación fluida con las Ejecutivas nacionales. A pesar de lo cual, razones de partido han propiciado en ambos casos el apoyo suficiente a sus respectivos Presidentes autonómicos para no poner en riesgo la gobernación de la Comunidad y el crédito del propio partido.

Por último, si llega a haber un Gobierno de coalición, todo el análisis anterior quedaría alterado: ni el programa sería sólo del Presidente, ni la composición del Gobierno sería tan discrecional: uno y otra deberían ser pactados con los socios de Gobierno. Por lo mismo, las funciones presidenciales más importantes (presentación de una cuestión de confianza, disolución de la Asamblea, incluso la misma dirección política del Consejo de Gobierno) se verian muy mediatizadas $^{37}$.

37 Cfr. Torres del Moral, A. y obras citadas en la nota 36 . El mismo análisis podemos ver en SÁlz ARNálz, A.: Op. cit. (págs. $44-45$ y $49-50$ ). 